In the case of the accretion deposit (Fig. 3), I have shown experimentally that the proportion of fine grains in such a deposit is controlled mainly by the composition of the source from which the sand comes. A change of wind direction may therefore alter the fine-grain composition of the deposit, even assuming it to be growing steadily the while. In the same paper it was pointed out that the process of denudation tends to concentrate on the surface both extremely coarse and extremely fine grades. There are therefore two possible causes of the variation in texture.

The cause of the laminar structure of encroachment deposits is more interesting. Since the grains reach their final resting place after avalanching down the slope, the structure appears not to be due to direct wind action. From experiments with a mixture of coarse and fine sands, each dyed a different colour, it appears that when a dry sand avalanches down a slope the finer grains become concentrated along the internal surface of shear. When afterwards wetted, the mixture shows juat the same structure as the lower photograph in Fig. 3. This phenomenon does not seem to be generally known, and it may have useful applications in experimental soil mechanics.

That desert dunes are able to retain for very long periods the moisture received from rare showers of rain has long been recognized. But it has often puzzled me why such patches of moisture should be found beneath the sand surface in some places but not in others nearby. The explanation now seems to lie in the different structure of the two kinds of sand structure. When rain falls on an exposed encroachment deposit, the water seeps rapidly downwards along the old shear planes into depths at which it is immune from temperature changes and consequent evaporation. When, on the other hand, it falls on a firm accretion structure, it spreads out laterally along the surface layers of finer grain composition, and is hindered from sinking by the intervening lavers of sand which are lacking in fine grains. It therefore remains near the surface and is soon lost by evaporation.

In all cases where I found a moist zone beneath the dry surface, and in most cases where blades of dead grass were still visible on the dunes, the sand when wetted showed the steeply dipping structure of the encroachment formation. This is in accord, too, with my experience when motoring over dunes in very arid country, that areas containing occasional dead vegetation are to be avoided owing to their probable softness.

\footnotetext{
${ }^{1}$ Beadnell, H. J. L., Geog. J., 35, 387 (1910).

2 Jenkin, C. F., Proc. Inst. Civ. Eng., 234, 112 (1933).

Bagnold, R. A., Geog. J., 89, 432 (1937).

- Bagnold, R. A., Proc. Roy. Soc., A, 163, 250-264 (1937).
}

\title{
Researches in Hypnosis
}

$\mathrm{I}^{\mathrm{N}}$ a noteworthy article, the first to appear from the recently founded Institute of Experimental Psychology at Oxford, Dr. William Brown discusses "Hypnosis, Suggestibility and Progressive Relaxation" (Brit. J. Psych., 28, Part 4: April 1938). Originally delivered as a lecture to the British Psychological Society, it was again communicated, in an abridged form, to the Psychology Section of the British Association in 1937. The importance of its content justified this second communication at the Nottingham meeting, when many members of other sections had the opportunity of hearing and discussing it. Dr. Brown has been well advised to have the lecture printed.

Beginning with a brief outline of its history and development from the time of Mesmer, the author even more briefly expounds his own theory of hypnotism and a technique for inducing hypnosis, which may or may not include muscular relaxation. In his therapeutic practice, however, relaxation is always induced, beginning with the small muscles of the extremities, extending to the greater muscle groups of limbs and torso, and ending with all the lesser muscles involved in speech and vision. This process not only secures a calm and tranquil state of body, but also tends to extinguish both inner speech and visual imagery, which might support conscious activity and keep the mind alert. As Jacobson has experimentally shown, progressive relaxation is of the highest importance in many pathological conditions, and of itself may effect their alleviation and even removal. Combined with hypnosis, it secures a passive and receptive state of mind, during which curative suggestions may be given to the patient with every expectation of success. The physician also pays attention to the respiration of his patient, which is normally an autonomic function, in order to induce a slow, regular and rhythmical movement of diaphragm and intracostal muscles, which makes for still greater mental passivity. Though the author does not refer to him, Heyer has pointed out that this, the only autonomic process which is also under conscious control, enables us indirectly to influence the functioning of other autonomic processes. Dr. Brown, however, lays stress upon another way of securing control over the autonomic nervous system, namely, by means of the forming of conditionedreflexes. Hudgins, using Pavlov's method, has shown experimentally that the pupillar reflex can be 'conditioned' to the sound of the word 'contract' when, just after pronouncing it, a bright light is flashed upon the eye. In time, the pupil comes to contract when the subject of the experiment pronounces the word 'contract' himself, or even thinks it, thus enlarging the scope of his volitional control, even if only indirectly. The psychotherapeutic value of this process of conditioning would seem to be evident; since, as Dr. Brown points out, a word, or thought, may be associated with the operation of a drug, and in time come to act as a substitute for it.

What is, however, of greatest interest in this paper is the account given of the experiments upon the patellar reflex, carried out at the Oxford Institute by Dr. Brown himself, by which it was shown that normal sleep and the hypnotic condition can be distinguished by their several effects upon the knee-jerk. The subject was seated in a chair ; and every ten seconds a smart tap was given on the patellar tendon by an electrically controlled hammer. The excursion of the reflex movement was recorded upon the smoked paper of a kymograph by a lever which was connected by a thread passing over a pulley to the subject's foot, thus securing a continuous record. 
The method followed was to cause the subject to fixate his eyes upon a bright light, and to secure relaxation by suggestions of drowsiness, sleep and rhythmical breathing. The subject becomes deeply relaxed; and, though not asleep, his knee-jerks are abolished. But, when suggestions of a hypnotic kind (for example, that he cannot open his eyes) are given, the reflex manifests itself again.

A similar criterion of the distinction between sleep and hypnosis is found in the so-called psychogalvanic (or skin constrictor) reflex. The more relaxed the subject becomes, the more the body resistance rises; the less there is of 'alertness'. But, when hypnotic suggestions are given, the resistance falls. It would seem that hypnosis is a state of peculiar, though restricted, vigilance; whereas lethargy is a blend of hypnosis and drowsiness, or sleep.

These and like experiments show the possibility, and indicate the importance, of extending laboratory methods to the investigation of 'abnormal' and pathological states.

\section{The Arctic Fauna}

G REAT interest in arctic exploration during the last few decades has resulted in a large number of publications on its fauna, mostly descriptive in character and restricted either to certain areas or to groups of animals. The only comprehensive work on the subject is the well-known "Fauna Arctica," written by numerous contributors under the editorship of Roemer and Schaudinn, which contains extensive lists of animals, mostly devoid of any general information and useful mainly for the statistics of the fauna. The questions of the origin and evolution of the arctic fauna have been attacked by some zoogeographers; but their comprehensive treatment from a modern point of view was lacking. This gap is now filled by Prof. N. J. Kusnezov, who has succeeded in less than a hundred pages in present. ing a remarkably concise and clear survey of the whole problem.*

The term 'arctic', as understood by the author, comprises the territories occupied by the tundra proper and by the northernmost marginal belt of the forest zone with its scattered, stunted trees. An up-to-date list of the number of species in each group of animals is given, the total being about 5,500 species. The actual number of arctic species is estimated as at least three times as many. The number of vertebrates, except birds, is too small to permit reliable zoogeographical conclusions, while birds, although numerous (270 species), are represented almost exclusively by non-resident species, which spend in the arctic only a very short breeding period. Most of the invertebrates are still insufficiently studied; but insects are represented by an unexpectedly large number of species, particularly of Diptera, Hymenoptera, Coleoptera and Lepidoptera.

The existence of the arctic fauna under the peculiar environmental conditions of high latitudes undoubtedly suggests a long period of adaptation. Unfortunately, the physiological aspect of this adaptation remains unstudied and is probably not the same in different groups. One point, however, appears certain, namely, that the present composition of the arctic fauna is determined not so much by the thermal conditions of the arctic, as by nutritional interrelations of organisms, that is, primarily by plant life, which is mainly dependent on the peculiar seasonal distribution of daylight.

As regards the taxonomic composition of the arctic fauna, it proves to be most heterogeneous, including representatives of both primitive and highly specialized groups, while there is no group that may be regarded as specially adapted to arctic conditions. This

- Kusnezov, N. J. "The Arctic Fauna of Eurasia and its Origin". (In Russian with an English summary.) Trav. Inst. Zool. Acad. Sci. D.R.S.S., 5, Part 1, 1938; 85 pp. complexity of arctic fauna suggests a very chequered history. From a zoogeographer's point of view, this history can be best made intelligible by accepting the theory of longitudinal displacements of climatic zones (Koeppen-Wegener), causing corresponding migrations of animal population.

Among the various historical elements of the arctic fauna, an important place belongs to the 'euarctics', as the author calls endemic species now living only under arctic conditions, although they have no apparent ecological or physiological adaptations. The primary origin of the euaretics is obscure, but in Lepidoptera, for example, a taxonomic analysis of euarctic forms points clearly to their origin from the Tertiary fauna of the Angaran continent. Moreover, it is highly probable that many of the euarctics should be regarded not as postglacial immigrants into the arctic zone, but as relics of a preglacial fauna. This assumption is based on quite legitimate doubts of the severity of conditions during glaciation (which is usually taken for granted), and on the existence of numerous plants and animals under most intense arctic conditions, for example, in Greenland and on arctic islands.

The Quaternary glaciations resulted in a southward migration of most arctic organisms which found temporary refuges on the edges of glaciated areas. This was followed by return migrations during the inter-glacial periods, and these repeated movements led to the great complexity in the composition of the present Arctic population, in which, apart from the Angaran elements, those derived from 'refuge areas' in western Europe, in the centre and extreme east of Asia, and in the north-west of North America, can be distinguished.

Incidentally, the analysis of the Arctic fauna throws some light on the similar great heterogeneity of the more southern faunas, namely, the palæarctic and the nearctic, and the author insists very emphatically that the time has come when the current conception of rigidly defined zoogeographical regions should be drastically revised on the basis of modern ecological and geological knowledge and theories.

The work of Prof. Kusnezov deserves close study not only by those specially interested in the arctic, but also by biologists in general, since it represents a courageous attempt to discuss a wide biogeographical problem from a thoroughly modern point of view and with a healthy critical attitude towards generalizations that are generally accepted merely because they are often repeated.

A good bibliography on the arctic fauna (and partly flora) comprising twelve pages concludes this interesting paper.

B. P. UVarov. 